\title{
DEVELOPMENT OF SURFACE ROUGHNESS MODEL IN TURNING PROCESS OF 3X13 STEEL USING TIAIN COATED CARBIDE INSERT
}

\author{
Nhu-Tung Nguyen $\bowtie$ \\ HaUI Institute of Technology - HIT ${ }^{1}$ \\ tungnn@haui.edu.vn \\ Do Duc Trung \\ Faculty of Mechanical Engineering ${ }^{l}$ \\ Hanoi University of Industry \\ ${ }^{1} 298$ Cau Dien str., Bac Tu Liem District, Hanoi, Vietnam, 100000
}

$\triangle$ Corresponding author

\begin{abstract}
Surface roughness that is one of the most important parameters is used to evaluate the quality of a machining process. Improving the accuracy of the surface roughness model will contribute to ensure an accurate assessment of the machining quality. This study aims to improve the accuracy of the surface roughness model in a machnining process. In this study, Johnson and BoxCox transformations were successfully applied to improve the accuracy of surface roughness model when turning 3 X13 steel using TiAlN insert. Four input parameters that were used in experimental process were cutting velocity, feed rate, depth of cut, and insert-nose radius. The experimental matrix was designed using Central Composite Design (CCD) with 29 experiments. By analyzing the experimental data, the influence of input parameters on surface roughness was investigated. A quadratic model was built to explain the relationship of surface roughness and the input parameters. Box-Cox and Johnson transformations were applied to develop two new models of surface roughness. The accuracy of three surface roughness models showed that the surface roughness model using Johnson transformation had the highest accuracy. The second one model of surface roughness is the model using Box-Cox transformation. And surface roughness model without transformation had the smallest accuracy. Using the Johnson transformation, the determination coefficient of surface roughness model increased from $80.43 \%$ to $84.09 \%$, and mean absolute error reduced from $19.94 \%$ to $16.64 \%$. Johnson and Box-Cox transformations could be applied to improve the acuaracy of the surface roughness prediction in turning process of $3 \mathrm{X} 13$ steel and can be extended with other materials and other machining processes.
\end{abstract}

Keywords: Surface Roguhness, Turrning, TiAlN insert, 3X13 steel, Box-Cox transformation, Johnson transformation.

DOI: $10.21303 / 2461-4262.2021 .001937$

\section{Introduction}

In machining processes of the mechanical products, one of the most methods that are commonly used is turning process. The work volume that is performed by turning processes is about $30 \div 40 \%$ of the total workload of the machining processes, and the number of turning machines are about $25 \div 50 \%$ of the total number of machine tools in the machining workshop [1]. The surface roughness of the machining surface has significant influence on the workability and life of the products. So, surface roughness is often chosen as a criterion to evaluate the quality and efficiency of the machining process in general and in turning processes in particular.

Investigation of the influence of machining parameters on the surface roughness is the basic in determination of technology parameters to ensure the requirement of the surface roughness after machining. Many studies that were performed follow this direction for the specific cases of workpiece materials and cutter materials. The influence of cutting velocity, feed rate, and depth of cut on the surface roughness was investigated in turning process of mild steel using high speed steel (HSS) cutter [2]. This study showed that the surface roughness decreased with increasing of cutting velocity. While the surface roughness increased with increasing of feed rate or increasing of cutting depth. The results were the same as in the case using the HSS cutter to turn the aluminum alloy [3]. Cutting velocity, feed rate, depth of cut, and coolant concentration were chosen to investigate the influence of them on the surface roughness when turning the AISI 1040 steel by carbide 
insert (CNMG 431-PF 4225) [4]. This study concluded that feed rate was the most influence parameter on the surface roughness. Surface roughness increased with increasing of cutting velocity, feed rate, and coolant concentration. But the tendency of surface roughness changed in the opposite direction with increasing of cutting depth.

The cutter with material ceramic with an $\mathrm{Al}_{2} \mathrm{O}_{3}+\mathrm{TiC}$ matrix (KY1615) was used to turn AISI 1050 steel [5]. This study showed that feed rate and depth of cut have significant influence on the surface roughness, while the cutting velocity has a negligible effect on the surface roughness. The influence of cutting velocity, feed rate, depth of cut, and insert nose radius on the surface roughness was investigated in turning process of sintering of AlSi10MG alloy powder using sintered carbide insert [6]. This study concluded that in four above parameters, only two parameters that were feed rate and depth of cut have significant influence on the surface roughness. The influence of cutting velocity, feed rate, cutter materials (coating TiC and coating WC), and machining lubrication conditions (dry machining and machining using lubricating liquid) on the surface roughness was investigated in turning process of AISI 1060 [7]. The results of this study showed that machining using lubricating liquid, the surface roughness was smaller than that one in case dry machining, machining using the coated WC insert, the surface roughness was smaller than that one in case machining using coated $\mathrm{TiC}$ insert, besides, the surface roughness was mall with increasing of cutting velocity and decreasing of feed rate.

The coated TiC insert was used to turn the AISI 1045 steel [8]. In this study, four parameters that were selected as the input parameters were cutting velocity, feed rate, depth of cut, and tool overhang. The analyzed results showed that only cutting velocity has a significant effect on the surface roughness. The experimental research was performed to investigate the influence of cutting velocity, feed rate, depth of cut, and insert nose radius on the surface roughness in turning process of AISI H11 tool steel using carbide cutter (TNGA, SANDVIK) [9]. This study showed that only cutting velocity and feed rate have a significant influence on the surface roughness. The tungsten carbide insert was used to investigate the influence of the cutting velocity, feed rate, and depth of cut on the surface roughness in turning process of the cold rolled alloyed steel [10]. This study showed that all these parameters have a significant effect on the surface roughness, in which cutting velocity has the most influence on the surface roughness, the second factor that has the influence on the surface roughness was feed rate, finally, it was the influence of the cutting depth on the surface roughness.

The results from the study [11] showed that in turning process of MDN250 steel using cubic boron nitride cutter, feed rate has a significant effect on the surface roughness, while cutting velocity and cutting depth have a negligible effect on the surface roughness.

The influence of cutting velocity, feed rate, and cutting depth on the surface roughness when turning the mild steel using coated carbide cutting tool was investigated in both cases wet and dry turning [12]. This study showed that in both wet and dry turning processes, feed rate has a significant influence on the surface roughness, when increasing the feed rate, the surface roughness increased. The influence of cutting velocity, feed rate, depth of cut, and insert nose radius on the surface roughness was examined in turning process of polyethylene (PE) using VCGX insert [13]. This study showed that cutting velocity, feed rate, and insert nose radius have a significant influence on the surface roughness, while cutting depth has a negligible effect on the surface roughness. The authors in study [14] concluded that when using uncoated cemented carbide cutting tool inserts to turn the stainless SAF 2507 steel, feed rate has a significant effect on the surface roughness, when increasing the feed rate, the surface roughness increased. While cutting velocity and cutting depth have a negligible effect on the surface roughness. The authors in study [15] concluded that when using the Sangeo DNMG 150608R-ST PS7220S tool to turn the titanium 6Al-4V ELI, feed rate also has a significant effect on the surface roughness, when increasing the feed rate, the surface roughness increased. While cutting velocity and cutting depth also have a negligible effect on the surface roughness.

From above literature review, it showed that cutting velocity, feed rate, depth of cut, and cutter nose radius are often chosen as the input parameters of the experimental process to survey the influence of them on the surface roughness. These parameters are easily changed by the 
workers when operating the machining machines. Other parameters such as vibrations, temperature, friction, etc. have the influence on the surface roughness. However, it is quite difficult to control these parameters in the machining processes. The above literature review also showed that for each specific case of workpiece material and cutter, the influence degrees of each cutting parameter (cutting velocity, feed rate, depth of cut, or cutter nose radius, etc.) on the surface roughness were different. So, it is necessary to investigate the influence of these parameters on the surface roughness in specific case.

The TiAlN coated carbide tools have many advantages such as high heat resistance, High abrasion resistance, etc. This type of cutting tool is widely used in both dry and wet machining processes. 3X13 steel (GOST-Russia) is a commonly used for the manufacture of components in the shipbuilding industry, oil and gas industry, chemical technology, food processing industry, and medical sector, and so on. Up to now, the studies that have been performed to investigate the effect of machining parameters on surface roughness when turning this steel are still quite limited. There have been not any studies that have been published on investigating the effect of technological parameters on the surface roughness when using TiAlN coated cutting tools to turn this steel. Therefore, it is necessary to perform the study using of TiAlN coated cutting tools to turn this steel.

In this paper, the experimental research has been carried out to solve the mentioned limitations. The surface roughness model showing the relationship between surface roughness and cutting velocity, feed rate, cutting depth, and tool nose radius has also been constructed based on the experimental data. To improve the accuracy of the roughness model in prediction of the surface roughness, two data transformations including Box-Cox transformation and Johnson transformation were also applied to propose two new models of the surface roughness. A comparison of the roughness prediction accuracy of the three constructed models was also performed in this study.

\section{Material and Method}

\section{1. Workpiece material}

In this study, 3X13 steel was the workpiece material that was used to perform the turning experiments. The workpiece dimensions were the diameter of $30 \mathrm{~mm}$ and the length of $320 \mathrm{~mm}$. Several workpieces that were used in experimental process were described in Fig. 1.

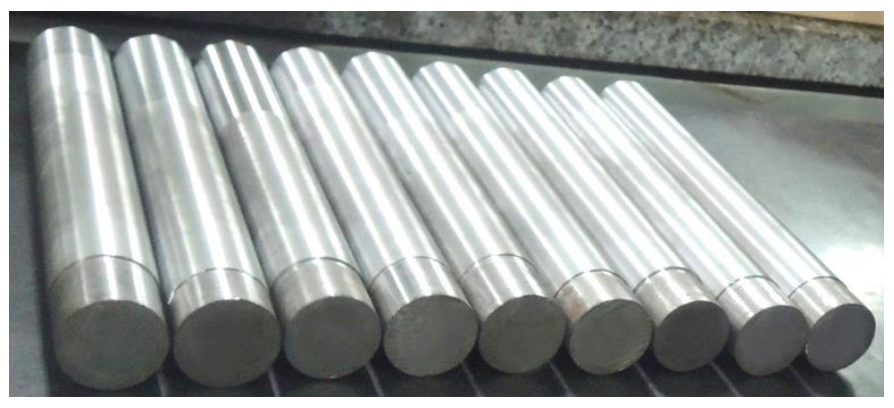

Fig. 1. Experimental workpieces

The workpieces have heat treated for archived $56 \mathrm{HRC}$ in hardness. According to the several standards, the quivalent signs of 3X13 steel were presented in Table 1.

Table 1

Equivalent signs of the $3 \mathrm{X} 13$ steel according to the several standards

\begin{tabular}{cccccccc}
\hline Russia & USA & Germany & Japan & England & Euro & Spain & China \\
\hline GOST & SAE & DIN & JIS & BS & EN & UNE & GB \\
$3 X 13$ & 420 & 1.4028 & SUS420J2 & 420 S45 & 1.4028 & F.3403 & 3 Cr13
\end{tabular}


In turning processes, the workpiece is clamped one end by a 3-pin chuck and one end is clamped by the central tip.

\section{2. Turning machine and cutter insert}

The turning machine that was used in this study was a conventional turning machine (or manual lathe), FEL-1440GMW of MAGNUM-CUT (Taiwan). The TiAlN coated carbide inserts (Lungaloy, Japan) were used to conduct the cutting processes. Five values of the insert nose radius were used including $0.4 \mathrm{~mm}, 0.6 \mathrm{~mm}, 0.8 \mathrm{~mm} .1 .0 \mathrm{~mm}$, and $1.2 \mathrm{~mm}$, respectively. A frequency control device (inverter) is connected to the lathe motor so that the machine can be adjusted the values of the spindle speed to adjust the cutting velocity as desired.

\section{3. Surface roughness tester}

In each experiment, the machining surface roughness was measured at least three times using a SI-301 surface roughness tester (Mitutoyo - Japan) was described in Fig. 2.

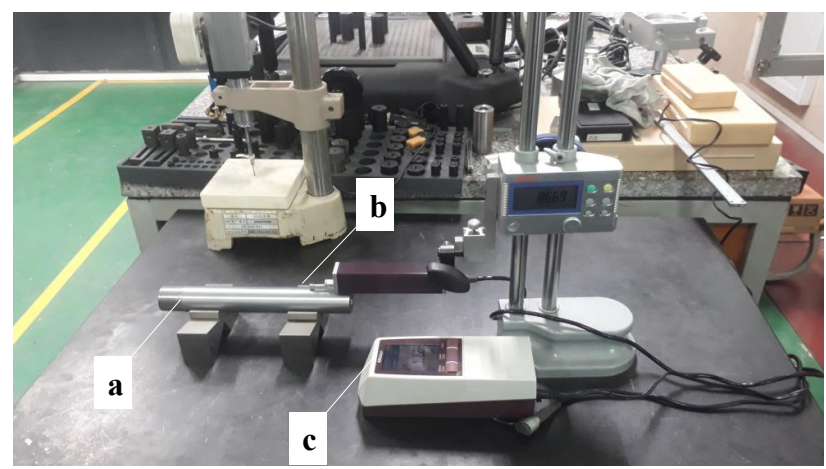

Fig. 2. Surface roughness SJ-301 tester: $a$ - Workpiece; $b$ - Sensor; $c$ - Processing box

The surface roughness is measured in a direction perpendicular to the direction of the cutting velocity, the standard length of measurement is chosen to be $0.8 \mathrm{~mm}$. The surface roughness value at each experiment is the average value of the successive measurements.

\section{4. Experimental plan}

The experiments were designed following the CCD matrix type. Four parameters that were chosen as the input parameters were workpiece velocity, feed rate, depth of cut, and insert nose radius. According to this experimental type, each input parameter was designed by five code levels including $-2,-1,0,1$, and 2 as presented in Table 2. So, the experimental matrix consists of 29 experiments as listed in Table 3.

Table 2

Input parameters and their levels

\begin{tabular}{|c|c|c|c|c|c|c|c|c|}
\hline \multirow{2}{*}{ Parameter } & \multirow{2}{*}{ Unit } & \multirow{2}{*}{ Symbol } & \multirow{2}{*}{ Code } & \multicolumn{5}{|c|}{ Value at levels } \\
\hline & & & & -2 & -1 & $\mathbf{0}$ & 1 & 2 \\
\hline Cutting velocity & $\mathrm{m} / \mathrm{min}$ & $v$ & $x_{1}$ & 80 & 100 & 120 & 140 & 160 \\
\hline Feed rate & $\mathrm{mm} / \mathrm{rev}$ & $f$ & $x_{2}$ & 0.06 & 0.08 & 0.1 & 0.12 & 0.14 \\
\hline Depth of cut & $\mathrm{mm}$ & $t$ & $x_{3}$ & 0.25 & 0.50 & 0.75 & 1.00 & 1.25 \\
\hline Insert nose radius & $\mathrm{mm}$ & $r$ & $x_{4}$ & 0.4 & 0.6 & 0.8 & 1.0 & 1.2 \\
\hline
\end{tabular}

The experiments were carried out in dry machining condition. To eliminate the effect of tool wear on the machining process, each insert is used only once time of cutting process. 
Table 3

Experimental matrix and results

\begin{tabular}{|c|c|c|c|c|c|c|c|c|c|c|c|c|}
\hline \multirow{2}{*}{ No. } & \multicolumn{4}{|c|}{ Code values } & \multicolumn{4}{|c|}{ Real values } & \multicolumn{4}{|c|}{ Surface roughness } \\
\hline & $x_{1}$ & $x_{2}$ & $x_{3}$ & $x_{4}$ & $v(\mathrm{~m} / \mathrm{min})$ & $f(\mathrm{~mm} / \mathrm{rev})$ & $t(\mathrm{~mm})$ & $r(\mathrm{~mm})$ & $R_{a 1}(\mu \mathrm{m})$ & $R_{a 2}(\mu \mathrm{m})$ & $R_{a 3}(\mu \mathrm{m})$ & $R_{a}(\mu \mathrm{m})$ \\
\hline 1 & 1 & -1 & -1 & 1 & 140 & 0.08 & 0.50 & 1.0 & 0.883 & 0.948 & 0.940 & 0.924 \\
\hline 2 & 0 & 0 & -2 & 0 & 120 & 0.10 & 0.25 & 0.8 & 0.799 & 0.768 & 0.631 & 0.732 \\
\hline 3 & -2 & 0 & 0 & 0 & 80 & 0.10 & 0.75 & 0.8 & 0.944 & 0.984 & 0.952 & 0.960 \\
\hline 4 & -1 & 1 & -1 & -1 & 100 & 0.12 & 0.50 & 0.6 & 1.271 & 1.344 & 1.380 & 1.332 \\
\hline 5 & -1 & 1 & -1 & 1 & 100 & 0.12 & 0.50 & 1.0 & 1.065 & 1.068 & 1.071 & 1.068 \\
\hline 6 & 0 & 0 & 0 & 0 & 120 & 0.10 & 0.75 & 0.8 & 0.484 & 0.432 & 0.417 & 0.444 \\
\hline 7 & -1 & -1 & 1 & -1 & 100 & 0.08 & 1.00 & 0.6 & 0.532 & 0.576 & 0.547 & 0.552 \\
\hline 8 & 1 & -1 & 1 & 1 & 140 & 0.08 & 1.00 & 1.0 & 0.593 & 0.612 & 0.631 & 0.612 \\
\hline 9 & -1 & -1 & -1 & -1 & 100 & 0.08 & 0.50 & 0.6 & 0.545 & 0.540 & 0.536 & 0.540 \\
\hline 10 & 1 & 1 & 1 & 1 & 140 & 0.12 & 1.00 & 1.0 & 0.799 & 0.768 & 0.738 & 0.768 \\
\hline 11 & 0 & 0 & 0 & -2 & 120 & 0.10 & 0.75 & 0.4 & 0.666 & 0.684 & 0.666 & 0.672 \\
\hline 12 & -1 & -1 & 1 & 1 & 100 & 0.08 & 1.00 & 1.0 & 0.484 & 0.528 & 0.500 & 0.504 \\
\hline 13 & -1 & 1 & 1 & -1 & 100 & 0.12 & 1.00 & 0.6 & 1.198 & 1.224 & 1.142 & 1.188 \\
\hline 14 & 1 & 1 & 1 & -1 & 140 & 0.12 & 1.00 & 0.6 & 1.912 & 1.980 & 1.940 & 1.944 \\
\hline 15 & 0 & 0 & 0 & 0 & 120 & 0.10 & 0.75 & 0.8 & 0.424 & 0.420 & 0.417 & 0.420 \\
\hline 16 & 0 & 0 & 0 & 0 & 120 & 0.10 & 0.75 & 0.8 & 0.399 & 0.480 & 0.452 & 0.444 \\
\hline 17 & 0 & 0 & 0 & 0 & 120 & 0.10 & 0.75 & 0.8 & 0.399 & 0.396 & 0.428 & 0.408 \\
\hline 18 & 0 & 0 & 0 & 2 & 120 & 0.10 & 0.75 & 1.2 & 0.399 & 0.456 & 0.405 & 0.420 \\
\hline 19 & 1 & -1 & -1 & -1 & 140 & 0.08 & 0.50 & 0.6 & 0.339 & 0.300 & 0.298 & 0.312 \\
\hline 20 & 1 & -1 & 1 & -1 & 140 & 0.08 & 1.00 & 0.6 & 0.629 & 0.612 & 0.559 & 0.600 \\
\hline 21 & 1 & 1 & -1 & 1 & 140 & 0.12 & 0.50 & 1.0 & 0.774 & 0.732 & 0.726 & 0.744 \\
\hline 22 & -1 & -1 & -1 & 1 & 100 & 0.08 & 0.50 & 1.0 & 0.629 & 0.600 & 0.571 & 0.600 \\
\hline 23 & -1 & 1 & 1 & 1 & 100 & 0.12 & 1.00 & 1.0 & 1.839 & 1.860 & 1.916 & 1.872 \\
\hline 24 & 2 & 0 & 0 & 0 & 160 & 0.10 & 0.75 & 0.8 & 0.702 & 0.672 & 0.607 & 0.660 \\
\hline 25 & 0 & 2 & 0 & 0 & 120 & 0.14 & 0.75 & 0.8 & 1.404 & 1.440 & 1.440 & 1.428 \\
\hline 26 & 0 & -2 & 0 & 0 & 120 & 0.06 & 0.75 & 0.8 & 0.411 & 0.408 & 0.405 & 0.408 \\
\hline 27 & 1 & 1 & -1 & -1 & 140 & 0.12 & 0.50 & 0.6 & 0.968 & 0.936 & 0.904 & 0.936 \\
\hline 28 & 0 & 0 & 2 & 0 & 120 & 0.10 & 1.25 & 0.8 & 2.347 & 2.328 & 2.332 & 2.336 \\
\hline 29 & 0 & 0 & 0 & 0 & 120 & 0.10 & 0.75 & 0.8 & 0.496 & 0.432 & 0.476 & 0.468 \\
\hline
\end{tabular}

\section{Experimental Results and Discussion}

\section{1. Influence of input parameters on the surface roughness}

Experimental results are presented in Table 3. Minitab 16 statistical software was used to analyze the effect of input parameters on the surface roughness, in which level of significance was chosen to be 0.05 . The analyzed results are described in Fig. 3.

From the results in this figure, it showed that the feed rate was the parameter that has the greatest influence on the surface roughness, followed by the influence of the cutting depth. The cutting velocity and insert nose radius have a negligible effect on the surface roughness. Besides, in this study, the influence of some other parameters on surface roughness has not been mentioned such as tool length, tool nose angle, tool materials, etc. And investigation of the determination of the influence of more parameters on the machined surface roughness is the next research direction of this study. 


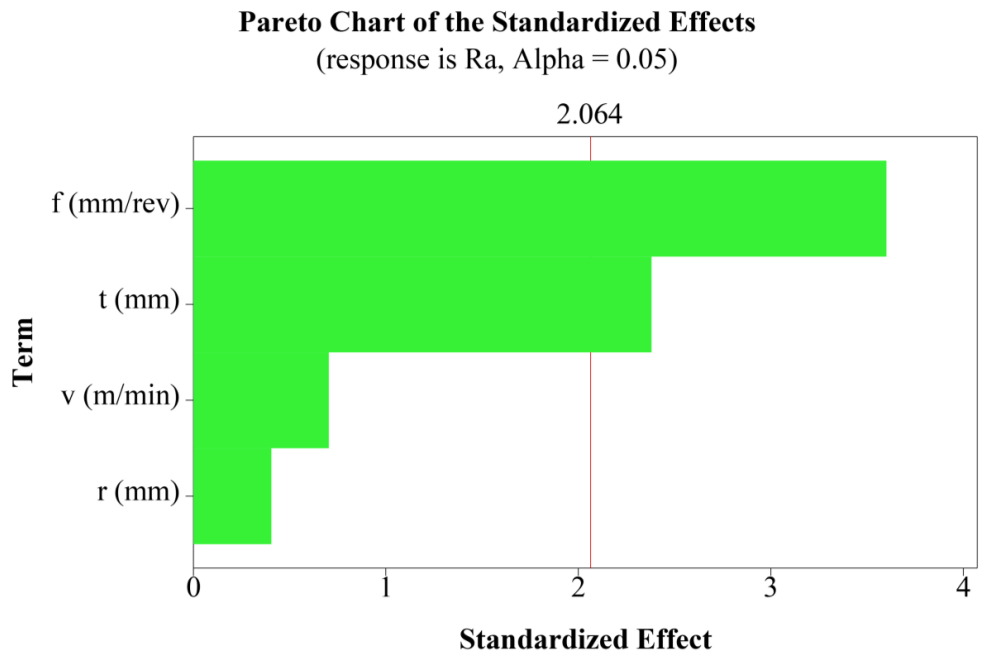

Fig. 3. Pareto diagram about the influence of input parameters on $R_{a}$

\section{2. Surface roughness regression model without transformation methods}

From the experimental data in Table 3, Minitab 16 statistical software was also used to build the surface roughness model as expressed by eq. (1). This model was built with the determination coefficient R-Sp was $80.34 \%$. The mean of this coefficient was presented in detail in reference number [16]. The surface roughness in turning process was modeled as a quadratic regression of the input parameters in this study.

$$
\begin{aligned}
& R_{a}=0.4368-0.059 \cdot x_{1}+0.302 \cdot x_{2}+0.19967 \cdot x_{3}-0.034 \cdot x_{4}+0.08563 \cdot x_{1}^{2}+ \\
& +0.11263 \cdot x_{2}^{2}+0.26663 \cdot x_{3}^{2}+0.01963 \cdot x_{4}^{2}-0.0825 \cdot x_{1} \cdot x_{2}+0.027 \cdot x_{1} \cdot x_{3}- \\
& -0.0735 \cdot x_{1} \cdot x_{4}+0.1125 \cdot x_{2} \cdot x_{3}-0.099 \cdot x_{2} \cdot x_{4}-0.0465 \cdot x_{3} \cdot x_{4} .
\end{aligned}
$$

The surface roughness model in formula (1) is consistent with the input data set at the determination coefficient of $80.43 \%$. To improve the accuracy of the surface roughness model, this study was used the Box-Cox and the Johnson transformation to convert the dataset. However, these two transformations should usually be applied only when the input dataset is not distributed according to the standard distribution [17]. Therefore, before performing data transformations, the distribution law of the dataset is assessed based on the experimental data.

The results of evaluating the distribution law of the surface roughness dataset were presented in Fig. 4.

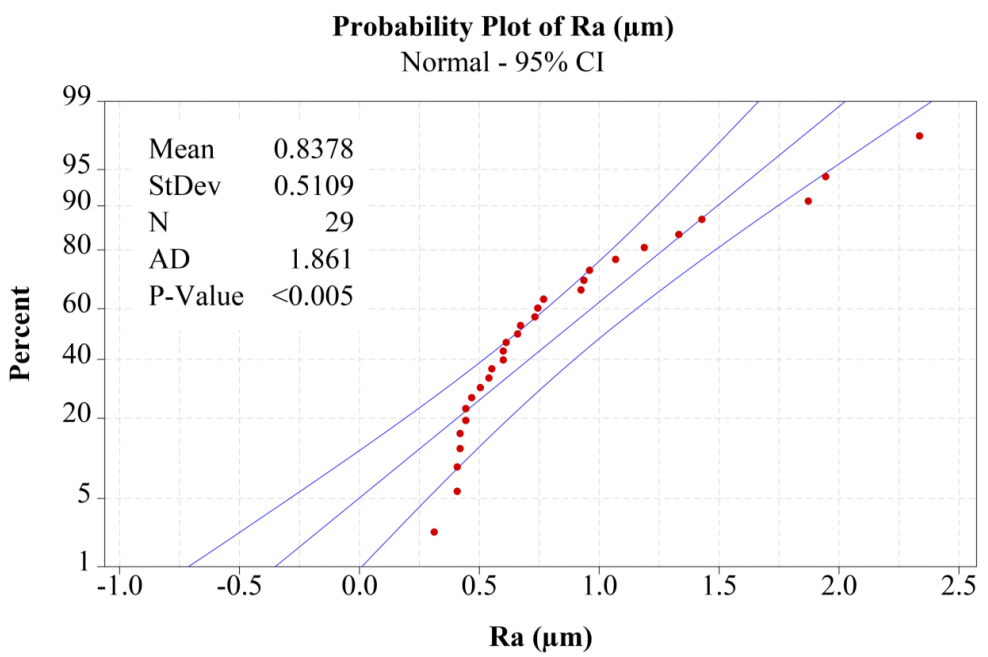

Fig. 4. The distribution law of experimental surface roughness 
Fig. 4 showed that the data is quite deviated from the standard line, on the other hand, P-value was 0.005 , much smaller than the significance level. So, it showed that the surface roughness dataset is not distributed according to the standard distribution. This is a necessary condition to perform the data transformation according to Box-Cox and Johnson transformations.

\section{3. Surface roughness model using Box-Cox transformation}

Box-Cox transformation was used to transform the dataset of surface roughness. Box-Cox transformation was performed by the eq. (2), [17]:

$$
\left\{\begin{array}{l}
X^{\prime}=X^{\lambda} \quad \text { when } \lambda \neq 0, \\
X^{\prime}=\ln (X) \text { when } \lambda=0,
\end{array}\right.
$$

where $X^{\prime}$ are the values of new data; $X$ are the values of initial data; $\lambda$ is the transformation exponent number.

The value of $\lambda$ is determined by the detection method so that the standard error of the transformed dataset is smallest. Box-Cox transformation performed the detection of $\lambda$ in the range of -5 to 5 , then rounded to one of the common values as shown in Table 4 [17].

The dataset of surface roughness after transformation was listed in Table 5. This dataset has the law of distribution as shown in Fig. 5. This figure showed that the dataset was quite close to the standard line, and the P-value was 0.678 , much larger than the significance level, this analyzed result confirmed that the dataset after the Box-Cox transformation was distributed according to the standard distribution.

Table 4

Normal values of $\lambda$ in Box - Cox transformation

\begin{tabular}{cc}
\hline$\lambda$ values & Transformation equations \\
\hline$\lambda=2.0$ & $X^{\prime}=X^{2}$ \\
$\lambda=0.5$ & $X^{\prime}=\sqrt{X}$ \\
$\lambda=0.0$ & $X^{\prime}=\ln (X)$ \\
$\lambda=-0.5$ & $X^{\prime}=1 / \sqrt{X}$ \\
$\lambda=-1$ & $X^{\prime}=1 / X$ \\
$\lambda=-2$ & $X^{\prime}=1 / X^{2}$
\end{tabular}

Table 5

The dataset of surface roughness after performing the transformations

\begin{tabular}{cccc}
\hline No. & $\boldsymbol{R}_{\boldsymbol{a}}(\boldsymbol{\mu} \mathbf{m})$ & After Box-Cox transformation (dimensionless) & After Johnson transformation (dimensionless) \\
\hline $\mathbf{1}$ & $\mathbf{2}$ & $\mathbf{3}$ & $\mathbf{4}$ \\
\hline 1 & 0.924 & 1.08225 & 0.57581 \\
2 & 0.732 & 1.36612 & 0.20300 \\
3 & 0.960 & 1.04167 & 0.63171 \\
4 & 1.332 & 0.75075 & 1.06967 \\
5 & 1.068 & 0.93633 & 0.78161 \\
6 & 0.444 & 2.25225 & -0.95976 \\
7 & 0.552 & 1.81159 & -0.36492 \\
8 & 0.612 & 1.63399 & -0.13703 \\
9 & 0.540 & 1.85185 & -0.41734 \\
10 & 0.768 & 1.30208 & 0.28515 \\
11 & 0.672 & 1.48810 & 0.04795 \\
12 & 0.504 & 1.98413 & -0.59222
\end{tabular}


Continuation of Table 5

\begin{tabular}{cccc}
\hline $\mathbf{1}$ & $\mathbf{2}$ & $\mathbf{3}$ & $\mathbf{4}$ \\
\hline 13 & 1.188 & 0.84175 & 0.92379 \\
14 & 1.944 & 0.51440 & 1.51496 \\
15 & 0.420 & 2.38095 & -1.14000 \\
16 & 0.444 & 2.25225 & -0.95976 \\
17 & 0.408 & 2.45098 & -1.23764 \\
18 & 0.420 & 2.38095 & -1.14000 \\
19 & 0.312 & 3.20513 & -2.08774 \\
20 & 0.600 & 1.66667 & -0.17864 \\
21 & 0.744 & 1.34409 & 0.23118 \\
22 & 0.600 & 1.66667 & -0.17864 \\
23 & 1.872 & 0.53419 & 1.47250 \\
24 & 0.660 & 1.51515 & 0.01368 \\
25 & 1.428 & 0.70028 & 1.15546 \\
26 & 0.408 & 2.45098 & -1.23764 \\
27 & 0.936 & 1.06838 & 0.59482 \\
28 & 2.336 & 0.42808 & 1.71683 \\
29 & 0.468 & 2.13675 & -0.79947
\end{tabular}

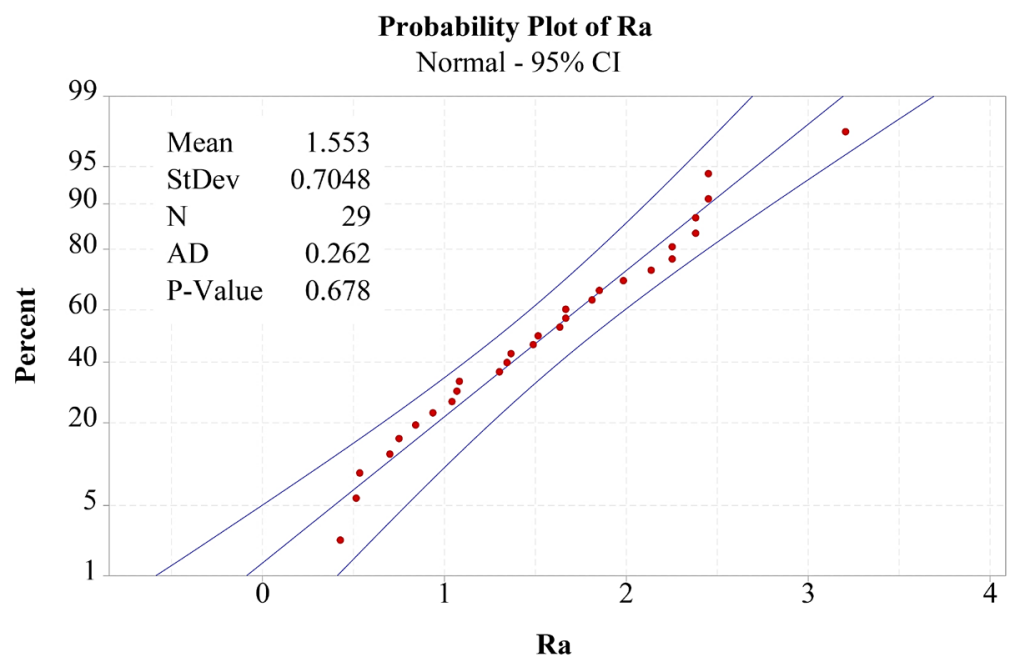

Fig. 5. The distribution law of the dataset after performing the Box-Cox transformation

The diagram of the Box-Cox transformation was described in Fig. 6. From this figure, the value of $\lambda$ was -1 . So, using Box-Cox transformation, the model of surface roughness was $X^{\prime}=1 / X$ as presented in Table 4 .

$$
R_{a}=\left\{\begin{array}{l}
2.29464+0.09945 \cdot x_{1}-0.46299 \cdot x_{2}-0.14553 \cdot x_{3}+0.02329 \cdot x_{4}-0.25977 \cdot x_{1}^{2}- \\
-0.18546 \cdot x_{2}^{2}-0.35510 \cdot x_{3}^{2}-0.09574 \cdot x_{4}^{2}+0.05576 \cdot x_{1} \cdot x_{2}-0.09680 \cdot x_{1} \cdot x_{3}- \\
-0.05985 \cdot x_{1} \cdot x_{4}-0.01235 \cdot x_{2} \cdot x_{3}+0.19435 \cdot x_{2} \cdot x_{4}+0.5417 \cdot x_{3} \cdot x_{4}
\end{array}\right\}^{-1}
$$

Applying Box-Cox transformation, the surface roughness model was developed as in eq. (3). This model has the determination coefficient R-Sq of $83.64 \%$. 


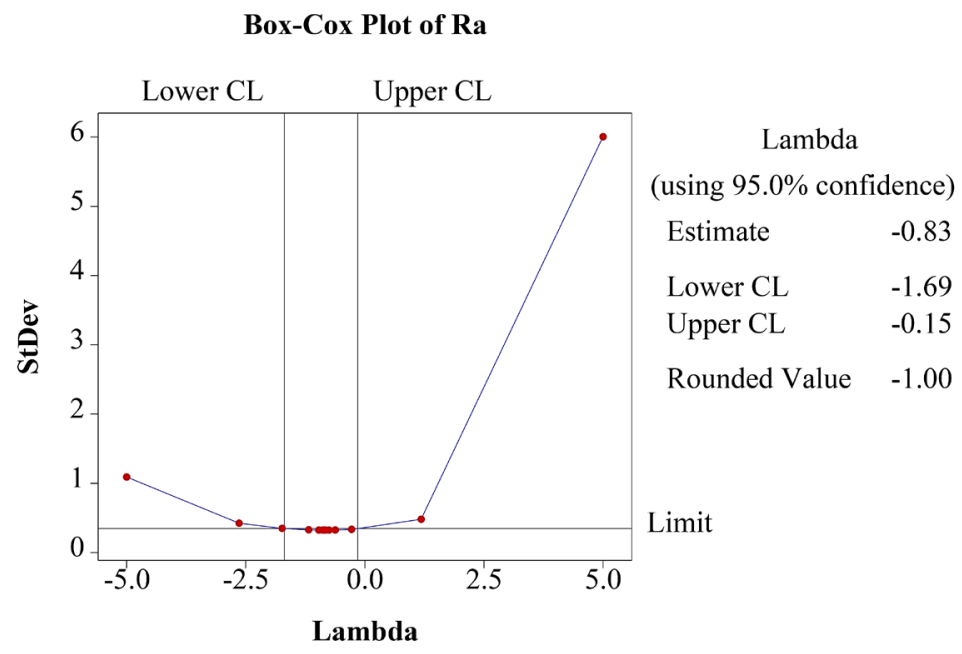

Fig. 6. The diagram of Box-Cox transformation

\section{4. Surface roughness model using Johnson transformation}

A diagram of the data transformation using the Johnson transformation was shown in Fig. 7. The upper left corner of this figure showed the distribution rule of the surface roughness without data transformation. This issue has been discussed in section 3. 2 .

Johnson Transformation for Ra
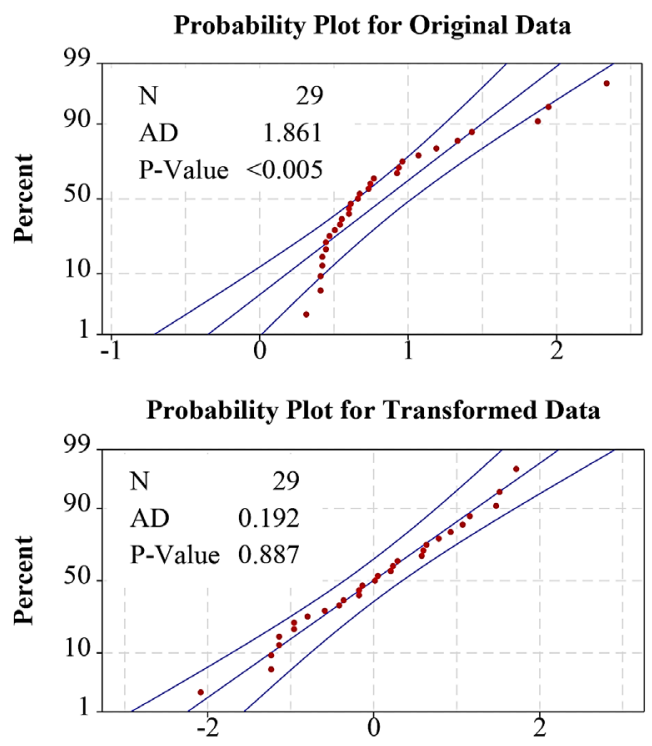

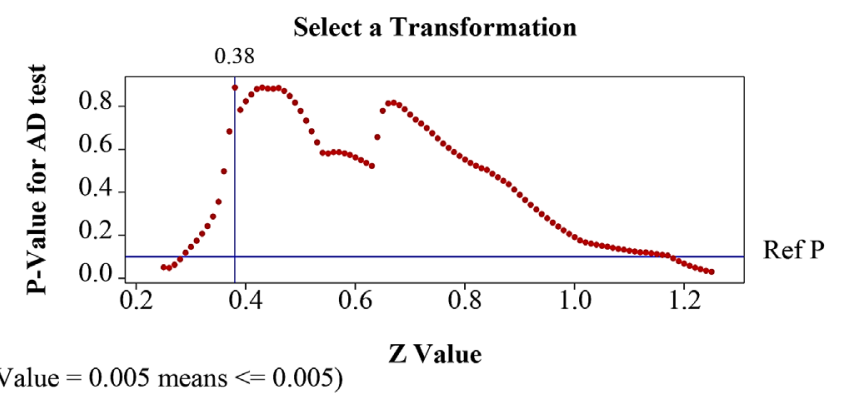

P-Value for Best Fit: 0.887244

Z for Best Fit: 0.38

Best Transformation Type: SU

Transformation function equals

$-1.64559+0.913329 * A \sinh ((\mathrm{X}-0.362069) / 0.0994914)$

Fig. 7. The diagram of Johnson transformation

$$
R_{a}=0.362069+0.0994914 \cdot \operatorname{Sinh}\left(\begin{array}{l}
0.68503-0.14288 \cdot x_{1}+0.68616 \cdot x_{2}+0.24552 \cdot x_{3}- \\
-0.04526 \cdot x_{4}+0.37545 \cdot x_{1}^{2}+0.27588 \cdot x_{2}^{2}+ \\
+0.54988 \cdot x_{3}^{2}+0.13766 \cdot x_{4}^{2}-0.09218 \cdot x_{1} \cdot x_{2}+ \\
+0.13594 \cdot x_{1} \cdot x_{3}+0.05746 \cdot x_{1} \cdot x_{4}+0.04681 \cdot x_{2} \cdot x_{3}- \\
-0.27711 \cdot x_{2} \cdot x_{4}-0.21332 \cdot x_{3} \cdot x_{4}
\end{array}\right) \text {. }
$$

The lower left corner showed the distribution rule of the dataset after performing the Johnson transformation. This figure showed that the data set after transformation was quite close to the standard line, the P-value was 0.887 , also much larger than the significance level. Therefore, it is possible to confirm that the dataset after performing the Johnson transformation distributed 
according to the standard distribution. This observation also showed that it is suitable conclusion when observing the upper right figure. The lower right part of this figure showed the relationship between the dataset before and after peforming the data transformation. The values of the dataset after performing the Johnson transformation were also listed in Table 5. From these results, a new model of the surface roughness was proposed as expressed by eq. (4). This model has a determination coefficient $R-S q$ of $84.09 \%$.

\section{5. Comparison of the surface roughness models}

Three surface roughness models presented in eq. (1), (3), (4) and the values of the input parameters in Table 3 were used to predict the surface roughness. The predicted results of surface roughness were listed in Table 6.

Table 6

Surface roughness by measurement and prediction

\begin{tabular}{|c|c|c|c|c|c|c|c|}
\hline \multirow[b]{2}{*}{ No. } & \multirow{2}{*}{$\begin{array}{l}\text { Experimental } \\
\text { surface Rough- } \\
\text { ness } R_{a}(\mu \mathrm{m})\end{array}$} & \multicolumn{3}{|c|}{ Predicted surface roughness $R_{a}(\mu \mathrm{m})$} & \multicolumn{3}{|c|}{$\%$ Absolute error } \\
\hline & & $\begin{array}{c}\text { Without } \\
\text { transformation }\end{array}$ & $\begin{array}{l}\text { Box-Cox trans- } \\
\text { formation }\end{array}$ & $\begin{array}{l}\text { Johnson trans- } \\
\text { formation }\end{array}$ & $\begin{array}{l}\text { Without trans- } \\
\text { formation }\end{array}$ & $\begin{array}{l}\text { Box-Cox trans- } \\
\text { formation }\end{array}$ & $\begin{array}{l}\text { Johnson trans- } \\
\text { formation }\end{array}$ \\
\hline 1 & 0.924 & 0.567 & 0.5714 & 0.5636 & 38.67 & 38.16 & 39.00 \\
\hline 2 & 0.732 & 1.104 & 0.8581 & 0.9023 & 50.82 & 17.23 & 23.27 \\
\hline 3 & 0.96 & 0.897 & 0.9464 & 0.9475 & 6.53 & 1.42 & 1.30 \\
\hline 4 & 1.332 & 1.0927 & 1.3925 & 1.3149 & 17.97 & 4.54 & 1.28 \\
\hline 5 & 1.068 & 1.0667 & 1.0365 & 1.0433 & 0.13 & 2.95 & 2.32 \\
\hline 6 & 0.444 & 0.4368 & 0.4358 & 0.4357 & 1.62 & 1.85 & 1.87 \\
\hline 7 & 0.552 & 0.5640 & 0.5752 & 0.5716 & 2.17 & 4.20 & 3.55 \\
\hline 8 & 0.612 & 0.7020 & 0.6256 & 0.6246 & 14.70 & 2.22 & 2.06 \\
\hline 9 & 0.54 & 0.3507 & 0.4718 & 0.4697 & 35.06 & 12.63 & 13.02 \\
\hline 10 & 0.768 & 1.1680 & 0.8710 & 0.9199 & 52.08 & 13.41 & 19.78 \\
\hline 11 & 0.672 & 0.5833 & 0.5362 & 0.5362 & 13.20 & 20.21 & 20.20 \\
\hline 12 & 0.504 & 0.7480 & 0.5481 & 0.5542 & 48.41 & 8.75 & 9.95 \\
\hline 13 & 1.188 & 1.7560 & 3.4767 & 2.3622 & 47.81 & 192.65 & 98.84 \\
\hline 14 & 1.944 & 1.6740 & 1.9079 & 1.8236 & 13.89 & 1.86 & 6.19 \\
\hline 15 & 0.42 & 0.4368 & 0.4358 & 0.4357 & 4.00 & 3.76 & 3.73 \\
\hline 16 & 0.444 & 0.4368 & 0.4358 & 0.4357 & 1.62 & 1.85 & 1.87 \\
\hline 17 & 0.408 & 0.4368 & 0.4358 & 0.4357 & 7.06 & 6.81 & 6.78 \\
\hline 18 & 0.42 & 0.4473 & 0.5107 & 0.5026 & 6.50 & 21.59 & 19.66 \\
\hline 19 & 0.312 & 0.4907 & 0.3968 & 0.4083 & 57.26 & 27.17 & 30.88 \\
\hline 20 & 0.6 & 0.8120 & 0.5708 & 0.5848 & 35.33 & 4.87 & 2.53 \\
\hline 21 & 0.744 & 0.5827 & 0.7412 & 0.7211 & 21.69 & 0.37 & 3.08 \\
\hline 22 & 0.6 & 0.7207 & 0.6294 & 0.6291 & 20.11 & 4.90 & 4.85 \\
\hline 23 & 1.872 & 1.5440 & 0.8688 & 0.9691 & 17.52 & 53.59 & 48.23 \\
\hline 24 & 0.66 & 0.6613 & 0.6875 & 0.6876 & 0.20 & 4.17 & 4.18 \\
\hline 25 & 1.428 & 1.4913 & 1.5954 & 1.5335 & 4.43 & 11.72 & 7.39 \\
\hline 26 & 0.408 & 0.2833 & 0.4034 & 0.4047 & 30.56 & 1.12 & 0.81 \\
\hline 27 & 0.936 & 0.9027 & 0.7452 & 0.7615 & 3.56 & 20.38 & 18.64 \\
\hline 28 & 2.336 & 1.9027 & 1.7147 & 1.8150 & 18.55 & 26.60 & 22.30 \\
\hline 29 & 0.468 & 0.4368 & 0.4358 & 0.4357 & 6.67 & 6.88 & 6.91 \\
\hline
\end{tabular}

The deviation between the prediction and the experimental results was calculated by Eq. (5), where $R_{a \text { (measured) }}$ and $R_{a \text { (pred) }}$ are the surface roughness in the experimental and in the 
prediction, respectively. This deviation value was also listed in Table 6. Table 7 presented the results of comparing some parameters of three surface roughness models.

$$
\% \text { Absolute error }=\left|\frac{R_{a(\text { measured })}-R_{a(\text { predicted })}}{R_{a(\text { measured })}}\right| \cdot 100 .
$$

Table 7

Comparison of the surface roughness model

\begin{tabular}{lcc}
\hline \multicolumn{1}{c}{ Models } & $\boldsymbol{R}-\boldsymbol{S} \boldsymbol{q}$ & \% Mean absolute error \\
\hline Without transformation (Eq. 1) & $80.43 \%$ & 19.94 \\
With Box-Cox transformation (Eq. 3) & $83.64 \%$ & 17.86 \\
With Johnson transformation (Eq. 4) & $84.09 \%$ & 14.64
\end{tabular}

The data from Table 7 showed that the surface roughness model without data transformation has the smallest determination coefficient, the determination coefficient value of the surface roughness model using the Johnson transformation is biggest. For the deviation average between the predicted results and the experimental results, the surface roughness model without the data transformation has the maximum value, this value of the surface roughness model using Johnson transposition was the smallest value. So, it showed that in three proposed surface roughness models in this study, the model using the Johnson transformation has the highest accuracy, followed by the model using the Box-Cox transformation, the model without the data transformation has lowest accuracy. This study only stops at improving accuracy when predicting the machined surface roughness, the study using the prediction models to optimize the technological parameters will be the extension research direction of this study.

\section{Conclusions}

In four input parameters, the feed rate was the parameter that has the greatest influence on the surface roughness, followed by the influence of the cutting depth. The cutting velocity and insert nose radius have a negligible effect on the surface roughness.

In three proposed surface roughness models in this study, the model using the Johnson transformation has the highest accuracy, followed by the model using the Box-Cox transformation, the model without the data transformation has lowest accuracy.

The determination coefficients $(R-S q)$ of the surface roughness models without data transformation, using Box-Cox transformation, and using Johnson transformation were $80.43 \%$, $83.64 \%$, and $84.09 \%$, respectively. The deviation averages of three models between the predicted results and the experimental results were $19.94 \%, 17.86 \%$, and $14.64 \%$, respectively.

Box-Cox and using Johnson transformations can be applied to improve the accuracy of the machining surface roughness models in turning process of the 3X13 steel using TiAlN coated carbide insert.

\section{Acknowledgements}

We sincerely thanks for the support of Hanoi University of Industry (HaUI) during the implementation of this study.

\section{References}

[1] Tran, V. D., Nguyen, T. B., Nguyen, T. D., Nguyen, V. T., Tran, X. V. (2003). Manufacturing technology. Science and Technics Publishing House, Hanoi.

[2] Kumar, N., Kumar, P. (2016). Influence of machining parameters on surface roughness and dry friction. Engineering Solid Mechanics, 109-116. doi: https://doi.org/10.5267/j.esm.2016.3.001

[3] Bala Raju, J., Leela Krishna, J., Tejomurthy, P. (2013). Effect and optimization of machining parameters on cutting force and surface finish in turning of mild steel and aluminum. International Journal of Research in Engineering and Technology, 02 (11), 135-141. doi: https://doi.org/10.15623/ijret.2013.0211021 
[4] Yacov, S., Gurpreet, S. (2013). Determining the Influence of Various Cutting Parameters on Surface Roughness during Wet CNC Turning of AISI 1040 Medium Carbon Steel. IOSR Journal of Mechanical and Civil Engineering, 7 (2), 63-72. doi: https://doi.org/10.9790/1684-0726372

[5] Rao, C. J., Rao, D. N., Srihari, P. (2013). Influence of Cutting Parameters on Cutting Force and Surface Finish in Turning Operation. Procedia Engineering, 64, 1405-1415. doi: https://doi.org/10.1016/j.proeng.2013.09.222

[6] Struzikiewicz, G., Sioma, A. (2020). Evaluation of Surface Roughness and Defect Formation after The Machining of Sintered Aluminum Alloy AlSi10Mg. Materials, 13 (7), 1662. doi: https://doi.org/10.3390/ma13071662

[7] Mia, M., Bashir, M. A., Dhar, N. R. (2016). Effects of Cutting Parameters and Machining Environments on Surface Roughness in Hard Turning using Design of Experiment. AIP Conference Proceedings, 1754. doi: https://doi.org/10.1063/1.4958453

[8] Aleksandrovich, R. V., Siamak, G. (2014). The Effect of Tool Construction and Cutting Parameters on Surface Roughness and Vibration in Turning of AISI 1045 Steel Using Taguchi Method. Modern Mechanical Engineering, 04 (01), 8-18. doi: https://doi.org/10.4236/mme.2014.41002

[9] Saini, S., Ahuja, I. S., Sharma, V. S. (2012). Influence of cutting parameters on tool wear and surface roughness in hard turning of AISI H11 tool steel using ceramic tools. International Journal of Precision Engineering and Manufacturing, 13 (8), 1295-1302. doi: https://doi.org/10.1007/s12541-012-0172-6

[10] Dejan, T., Velibor, M. (2012). Modelling and Optimization of the Surface Roughness in the Dry Turning of the Cold Rolled Alloyed Steel Using Regression Analysis. Journal of the Brazilian Society of Mechanical Sciences and Engineering. XXXIV (1), 41-48.

[11] Yousefi, S., Zohoor, M. (2019). Effect of cutting parameters on the dimensional accuracy and surface finish in the hard turning of MDN250 steel with cubic boron nitride tool, for developing a knowledged base expert system. International Journal of Mechanical and Materials Engineering, 14 (1). doi: https://doi.org/10.1186/s40712-018-0097-7

[12] Yusuf, M., Anuar, K., Ismail, N. B., Sulaiman, S. (2011). Influence of Cutting Parameters on Surface Roughness for Wet and Dry Turning Process. Key Engineering Materials, 471-472, 233-238. doi: https://doi.org/10.4028/www.scientific.net/kem.471-472.233

[13] Lazarević, D., Madić, M., Janković, P., Lazarević, A. (2012). Cutting Parameters Optimization for Surface Roughness in Turning Operation of Polyethylene (PE) Using Taguchi Method. Tribology in Industry, 34 (2), 68-73. Available at: http://www. tribology.rs/journals/2012/2012-2/3.pdf

[14] Senthil Kumar, K., Senthilkumaar, J. S., Srinivasan, A. (2013). Reducing surface roughness by optimising the turning parameters. The South African Journal of Industrial Engineering, 24 (2), 78. doi: https://doi.org/10.7166/24-2-593

[15] Akkuş, H., Yaka, H. (2021). Experimental and statistical investigation of the effect of cutting parameters on surface roughness, vibration and energy consumption in machining of titanium 6Al-4V ELI (grade 5) alloy. Measurement, 167, 108465. doi: https://doi.org/10.1016/j.measurement.2020.108465

[16] Angela, D., Daniel, V. (1999). Design and Analysis of Experiments. Springer, 742. doi: https://doi.org/10.1007/b97673

[17] Nguyen, V. D., Nguyen, D. B. (2011). Design of experiment techniques. Science and technics publishing House, Hanoi.

Received date 23.02.2021

Accepted date 09.06.2021

Published date 23.07.2021
(C) The Author(s) 2021

This is an open access article under the Creative Commons CC BY license

How to cite: Nguyen, N.-T., Trung, D. D. (2021). Development of surface roughness model in turning process of $3 X 13$ steel using TiAlN coated carbide insert. EUREKA: Physics and Engineering, 4, 113-124. doi: https://doi.org/10.21303/2461-4262.2021.001937 